\title{
Associations between physical inactivity and sedentary behaviors among adolescents in 10 cities in China
}

\author{
You Chen ${ }^{1}$, Zhonghui Zheng ${ }^{1}$, Jinyao $\mathrm{Yi}^{2^{*}}$ and Shuqiao Yao ${ }^{2^{*}}$
}

\begin{abstract}
Background: Studies in western countries have revealed that excessive sedentary behavior is a major risk factor for physical inactivity in adolescents. This study was performed to investigate the association between sedentary behavior and physical inactivity in Chinese adolescents using a large-scale cross-sectional survey design.

Methods: This study was part of the 2011 Chinese Youth Risk Behavior Survey. Between March and September 2011, 10,214 11-18-year-olds were recruited for survey participation in 18 schools in 10 cities in China. Demographic and socioeconomic characteristics, and the prevalences of physical inactivity and sedentary behaviors, were examined. Correlations between sedentary behavior and physical inactivity were analyzed using baseline logistic regression.

Results: Among the final 9,901 students, physical inactivity ( 80\%) and sedentary behaviors (television viewing, 43\%; computer use, 30.2\%) were prevalent. More male than female students reported sedentary behaviors (television viewing $>2$ h: $5.5 \%$ vs. 3.9\%; computer use $>2$ h: $7.2 \%$ vs. 3.5\%; both $p<0.05$ ), but more males were physically active than females $(25.1 \%$ vs. $14.6 \% ; p<0.05)$. Television viewing was associated with lower odds of no physical activity (No $\mathrm{PA})$ in males [0-2 $\mathrm{h}$ : adjusted odds ratio $(\mathrm{AOR})=0.81,95 \%$ confidence interval $(\mathrm{Cl})=0.68-0.96 ;>4 \mathrm{~h}: \mathrm{OR}=0.34,95 \% \mathrm{Cl}=$ 0.18-0.64], but not in females. A similar pattern between insufficient physical activity and $>4 \mathrm{~h}$ TV viewing (AOR $=0.42$, $95 \% \mathrm{Cl}=0.23-0.76)$ and $>4 \mathrm{~h}$ computer use ( $\mathrm{AOR}=0.49,95 \% \mathrm{Cl}=0.30-0.78)$ was observed in males. In females, $0-2 \mathrm{~h}$ daily computer use was associated with higher odds of physical inactivity (No PA: AOR $=1.42,95 \% \mathrm{Cl}=1.10-1.82$; Insufficient PA: $A O R=1.58,95 \% \mathrm{Cl}=1.24-2.01$ ), while TV viewing was not associated with No PA or Insufficient PA. The probability of physical inactivity significantly increased with grade and decreased with socioeconomic status.

Conclusions: Physical inactivity and sedentary behaviors were prevalent in Chinese adolescents. Further support, including parental guidance and the provision of publicly accessible facilities, is necessary to encourage Chinese youths to engage sufficiently in physical activities.
\end{abstract}

Keywords: Adolescent, Physical activity, Computer, Television

\section{Background}

Physical inactivity among children and adolescents has become a global health concern because it has been strongly associated with many major diseases, such as obesity, diabetes, and cardiovascular disease [1-3]. In adolescents, physical activity (PA), defined as accumulation of at least $60 \mathrm{~min}$ of moderate-intensity physical activity (MVPA) daily [4], is critical to attain and maintain

\footnotetext{
*Correspondence: jinyaoyi@gmail.com; shuqiaoyao@163.com

${ }^{2}$ Medical Psychological Institute, Second Xiangya Hospital, Central South University, \#139 Ren-Min Zhong Road, Changsha 410011, China Full list of author information is available at the end of the article
}

appropriate bone strength and normal skeletal development [5]. Young adults who were physically inactive during adolescence are also more likely to be overweight than are their physically active counterparts [6]. The prevalence of physical inactivity, defined as not meeting the physical activity recommendation, is growing rapidly in adolescents $[7,8]$, underscoring the importance of identifying and understanding associated risk factors.

One hypothesis proposed to explain the pattern of physical inactivity in adolescents holds that sedentary behaviors (e.g., computer/video game use, television viewing) compete with social and physical activities during 
individuals' free time $[9,10]$. Adolescents are particularly likely to prefer television viewing and computer usage, commonly called "screen time", because they consider these activities to be more entertaining than physical activity $[9,10]$. Koezuka et al. [11] reported that television viewing was significantly associated with a higher risk of physical inactivity in Canadian youth, and the association was stronger in females than in males. And a metaanalysis produced similar conclusion [12]. However, other studies have shown no significant association between television viewing and physical inactivity $[13,14]$. Diverse findings regarding the relationship between computer use and PA have also been reported. In the Canadian Community Health Survey [11], male light computer users were likely to be more physically active than non-users, but their activity status did not differ from that of higher-level users. In females, physical inactivity was not significantly affected by any level of computer usage [11]. Another study conducted in Canada produced a similar conclusion that computer usage increased the probability of being physically active, but this finding applied to both males and females [13]. However, no association between computer/internet use and physical inactivity was found among adolescents in Singapore [15]. Other researchers have argued that computer use prevents youths from engaging in physical and social activities $[16,17]$. One potential explanation for these discrepancies is differences in socioeconomic status (SES) among cohorts, which are very likely to affect the availability of advanced technological devices. Indeed, the findings of recent studies have suggested that PA is positively associated with SES [18].

The increased prevalence of sedentary behavior and physical inactivity, as well as related health concerns, is not restricted to western countries. Rates of overweight, obesity, and physical inactivity are increasing in China, where cultural and economic patterns are distinct from those of developed countries [19]. The risks of these conditions are highest in China's rapidly growing cities and are exacerbated by current urban development practices and policies, including support for decentralization in land use planning, neighborhood gating, and policies and practices related to motor vehicle travel, transit planning, and bicycle and pedestrian infrastructure [20]. However, few studies of the relationship between physical inactivity and sedentary behaviors have been conducted in developing countries, such as China. Exploration of the mechanisms underlying this relationship is critical for preventive purposes.

In this study, which formed part of the 2011 Chinese Youth Risk Behavior Survey, a cross-sectional survey design was used to (a) describe the prevalence of physical inactivity and sedentary behavior among Chinese urban adolescents and (b) examine potential risk factors such as socio-economic status (SES) and sedentary behaviors, associated with physical inactivity among Chinese urban adolescents.

\section{Methods}

\section{Participants}

A cross-sectional survey design was used to recruit high-school students from March to September 2011. Participants were recruited from high schools in 10 cities in mainland China representing three economic growth levels: high (Beijing, Shanghai, and Guangzhou), moderate (Hangzhou, Suzhou, Chengdu, and Changsha), and low (Yinchuan, Shenyang, and Changping). Schools in these cities were stratified into categories representing high, medium, and low quality of education, which was based on academic performance. Then, one to two schools in each city with a medium-level quality of education were selected, and one to three classes in each grade were selected randomly in each school. Finally, 10,214 high school students (aged 11-18 years) in 18 schools attended anonymous survey. The ethics committee of the Second Xiangya Hospital of Central South University approved the study, and all participants and their parents provided written informed consent before the survey began.

\section{Measures \\ Outcome: physical activity}

The survey included one question from the Youth Risk Behavior Surveillance System (YRBSS) [21], developed by the Centers for Disease Control to monitor priority health-risk behaviors in youth: "During the past 7 days, on how many days were you physically active for a total of at least 60 minutes per day? (Add up all the time you spent in any kind of physical activity that increased your heart rate and made you breathe hard some of the time)." The cutoff point of $60 \mathrm{~min}$ was chosen because the Physical Activity Guidelines for Americans recommend that children and adolescents participate in moderate to vigorous physical activity (MVPA) for at least this long on most days of the week, preferably daily, to attain health benefits [3,22].

Estimation of PA was based on the self-reported number of days in a typical week on which respondents performed >60 min MVPA. Values were categorized as "no PA" (MVPA on 0 days), "insufficient PA" (MVPA on 1-4 days), and "PA" (MVPA on $\geq 5$ days).

\section{Primary predictors: sedentary behaviors}

Two YRBSS items were used to assess sedentary behaviors: "On an average school day, how many hours do you watch TV?" and "On an average school day, how many hours do you play video or computer games or use a computer for something that is not school work? (Include activities such as Xbox, PlayStation, Nintendo DS, iPod touch, Facebook, and the Internet)." Time 
spent on each activity was classified on a seven-point scale ranging from none to $\geq 5 \mathrm{~h}$. In the analysis, these categories were collapsed according to the distribution of responses, and time spent on sedentary behaviors was recoded as (i) none, (ii) $>0-2$ hours, (iii) $>2-4$ hours, (iv) $>4$ hours.

\section{Covariates: potential risk factors}

As potential risk factors for physical inactivity, demographic characteristics, body mass index (BMI), and SES were included as covariates to adjust for possible confounding effects. Respondents' grade levels at the time of the survey were classified as 7th-9th (junior stage) and

Table 1 Descriptive characteristics of the study sample

\begin{tabular}{|c|c|c|c|c|c|c|}
\hline \multirow[t]{2}{*}{ Variables } & \multicolumn{2}{|c|}{ Male $(N=5057)$} & \multicolumn{2}{|c|}{ Female $(N=4844)$} & \multicolumn{2}{|c|}{ Total $(N=9901)$} \\
\hline & $\mathbf{n}$ & $\%$ & $\mathrm{n}$ & $\%$ & $\mathrm{n}$ & $\%$ \\
\hline \multicolumn{7}{|l|}{ Grade } \\
\hline 7th-9th & 2587 & 51.2 & 2389 & 49.3 & 4976 & 50.3 \\
\hline 10th-12th & 2470 & 48.8 & 2455 & 50.7 & 4925 & 49.7 \\
\hline \multicolumn{7}{|l|}{ BMI categories* } \\
\hline Low or normal & 4149 & 82.0 & 4483 & 92.5 & 8623 & 87.2 \\
\hline Overweight & 570 & 11.3 & 245 & 5.1 & 815 & 8.2 \\
\hline Obesity & 338 & 6.7 & 116 & 2.4 & 454 & 4.6 \\
\hline \multicolumn{7}{|l|}{ Paternal level of education } \\
\hline Complete primary school or not & 1096 & 21.7 & 984 & 20.3 & 2080 & 21.0 \\
\hline Complete middle school & 1566 & 31.0 & 1599 & 33.0 & 3165 & 32.0 \\
\hline Complete high school & 1472 & 29.1 & 1369 & 28.3 & 2841 & 28.7 \\
\hline Complete higher education & 923 & 18.3 & 892 & 18.4 & 1815 & 18.3 \\
\hline \multicolumn{7}{|l|}{ Maternal level of education } \\
\hline Complete primary school or not & 1321 & 26.1 & 1191 & 24.6 & 2512 & 25.4 \\
\hline Complete middle school & 1702 & 33.7 & 1689 & 34.9 & 3391 & 34.2 \\
\hline Complete high school & 1328 & 26.3 & 1259 & 26.0 & 2587 & 26.1 \\
\hline Complete higher education & 706 & 14.0 & 705 & 14.6 & 1411 & 14.3 \\
\hline \multicolumn{7}{|l|}{ Household income per month ( $¥$ ) } \\
\hline$<1000$ & 233 & 4.6 & 211 & 4.4 & 444 & 4.5 \\
\hline $1000-1500$ & 498 & 9.8 & 518 & 10.7 & 1016 & 10.3 \\
\hline $1500-2000$ & 530 & 10.5 & 587 & 12.1 & 1117 & 11.3 \\
\hline $2000-3000$ & 893 & 17.7 & 862 & 17.8 & 1755 & 17.7 \\
\hline $3000-4000$ & 1001 & 19.8 & 928 & 19.2 & 1929 & 19.5 \\
\hline $4000-5000$ & 723 & 14.3 & 760 & 15.7 & 1483 & 15.0 \\
\hline$>5000$ & 1179 & 23.3 & 978 & 20.2 & 2157 & 21.8 \\
\hline \multicolumn{7}{|c|}{ Subject economic status (in province) } \\
\hline Low & 74 & 1.5 & 59 & 1.2 & 133 & 1.3 \\
\hline Low middle & 554 & 11.0 & 516 & 10.7 & 1070 & 10.8 \\
\hline Middle & 2447 & 48.4 & 2466 & 50.9 & 4913 & 49.6 \\
\hline High middle & 1592 & 31.5 & 1433 & 29.6 & 3025 & 30.6 \\
\hline High & 390 & 7.7 & 370 & 7.6 & 760 & 7.7 \\
\hline \multicolumn{7}{|c|}{ Subject economic status (in school)* } \\
\hline Low & 76 & 1.5 & 35 & 0.7 & 111 & 1.1 \\
\hline Low middle & 361 & 7.1 & 259 & 5.3 & 620 & 6.3 \\
\hline Middle & 2176 & 43.0 & 2175 & 44.9 & 4351 & 43.9 \\
\hline High middle & 1996 & 39.5 & 1939 & 40.0 & 3935 & 39.7 \\
\hline High & 448 & 8.9 & 436 & 9.0 & 884 & 3.9 \\
\hline
\end{tabular}

*Significant difference between male and female, $\mathrm{p}<0.05$. 
10th-12th (senior stage). BMI was categorized as low/ normal, overweight, and obese based on the Body Mass Index Reference for Screening Overweight and Obesity in Chinese School-age Children [23].

Objective SES indicators included family income and parents' education levels. Monthly family incomes were coded as <1000 RMB (1), 1000-1500 RMB (2), 15002000 RMB (3), 2000-3000 RMB (4), 3000-4000 RMB (5), 4000-5000 RMB (6), and > RMB 5000 (7). Parents' education levels were classified as "at least some primary school", "completed middle school", "completed high school", and "completed higher education".

Participants subjectively rated their SES in the province and the school using the Chinese version of the Scale of Subjective Status [24,25]. Responses were structured by a scale ranging from 1 to 10 , with 10 representing the highest SES (most money, best education, and most respected) and 1 representing the lowest SES (least money, minimal education, and least respected). Subjective SES scores were categorized as low $(1,2)$, low middle $(3,4)$, middle $(5,6)$, high middle $(7,8)$, and high $(9,10)$.

\section{Statistical analysis}

All statistical analyses were stratified by gender, given differences in behavioral patterns reported in previous studies [26,27]. Frequencies and prevalence rates are reported for categorical variables (Tables 1 and 2). Differences in demographic characteristics and prevalence rates between gender groups were analyzed by chisquared statistic. Analyses were performed using SAS software (ver. 9.2; SAS Institute Inc., Cary, NC, USA). Statistical significance was evaluated at the 0.05 level.
Baseline logistic regression was performed to estimate the association between physical inactivity and sedentary behaviors, with "physically active" serving as the reference level for the outcome. BMI, parents' education levels, monthly income, and subjective SES were treated as ordinal variables. First, each sedentary activity was separately added to the model, followed by adjustment for covariates. Then, the model was examined with the inclusion of both sedentary behaviors.

\section{Results}

\section{Descriptive characteristics}

List-wise deletion due to missing responses resulted in the exclusion of 313 students. Data from 9,901 students in the 7 th-12th grades $[5,057(51.8 \%)$ males, 4,844 (48.2\%) females] were included in the final analysis. The final 9,901 students ranged in age from 11 to 18 years $(15.06 \pm 1.81)$, and the age difference between male $(15.09 \pm 1.80)$ and female $(15.03 \pm 1.82)$ was not significant, $p>0.05$. Sample characteristics are summarized in Table 1. No marked difference in descriptive characteristics was observed between the excluded group and the entire study sample (all $p>0.05$ ), which supported the representativeness of the study sample (data not shown).

Higher prevalences of overweight and obesity were observed in male than in female students $(11.3 \%$ vs. $5.1 \%$ and $6.7 \%$ vs. $2.4 \%$, respectively; both $p<0.05$ ). Most covariates associated with SES were similar between genders, except more male than female students rated themselves having low SES in school (Table 1).

Table 2 Prevalence of physical inactivity and sedentary behaviors

\begin{tabular}{|c|c|c|c|c|c|c|}
\hline \multirow[t]{2}{*}{ Variables } & \multicolumn{2}{|c|}{ Male $(N=5057)$} & \multicolumn{2}{|c|}{ Female $(N=4844)$} & \multicolumn{2}{|c|}{ Total $(N=9901)$} \\
\hline & $\mathbf{n}$ & $\%$ & $\mathrm{n}$ & $\%$ & $\mathrm{n}$ & $\%$ \\
\hline \multicolumn{7}{|c|}{ Physical activity/inactivity time* } \\
\hline None & 1605 & 31.7 & 2345 & 48.4 & 3950 & 39.9 \\
\hline Insufficient & 2185 & 43.2 & 1794 & 37.0 & 3979 & 40.2 \\
\hline Active & 1267 & 25.1 & 705 & 14.6 & 1972 & 19.9 \\
\hline \multicolumn{7}{|c|}{ Television viewing* } \\
\hline None & 2634 & 52.1 & 3013 & 62.2 & 5647 & 57.0 \\
\hline$>0-2$ hours & 2142 & 42.4 & 1643 & 33.9 & 3785 & 38.2 \\
\hline$>2-4$ hours & 204 & 4.0 & 145 & 3.0 & 349 & 3.5 \\
\hline$>4$ hours & 77 & 1.5 & 43 & 0.9 & 120 & 1.2 \\
\hline \multicolumn{7}{|c|}{ Computer use* } \\
\hline None & 3339 & 66.0 & 3572 & 73.7 & 6911 & 69.8 \\
\hline$>0-2$ hours & 1355 & 26.8 & 1100 & 22.7 & 2455 & 24.8 \\
\hline$>2-4$ hours & 237 & 4.7 & 127 & 2.6 & 364 & 3.7 \\
\hline$>4$ hours & 126 & 2.5 & 45 & 0.9 & 171 & 1.7 \\
\hline
\end{tabular}

*Significant difference between male and female, $\mathrm{p}<0.05$. 
Table 3 Odds ratios (OR) and $95 \%$ confidence intervals $(95 \% \mathrm{Cl})$ of physical inactivity by sedentary behaviors for males $(\mathrm{N}=5057)$

\begin{tabular}{|c|c|c|c|c|c|c|c|c|}
\hline & \multicolumn{4}{|c|}{ No $P A^{1}$} & \multicolumn{4}{|c|}{ Insufficient $\mathrm{PA}^{2}$} \\
\hline & \multicolumn{2}{|c|}{ Univariate } & \multicolumn{2}{|c|}{ Multivariate } & \multicolumn{2}{|c|}{ Univariate } & \multicolumn{2}{|c|}{ Multivariate } \\
\hline & OR & $95 \% \mathrm{Cl}$ & OR & $95 \% \mathrm{Cl}$ & OR & $95 \% \mathrm{Cl}$ & OR & $95 \% \mathrm{Cl}$ \\
\hline \multicolumn{9}{|l|}{ Grade } \\
\hline 7th-9th & 1.00 & & 1.00 & & 1.00 & & 1.00 & \\
\hline 10th-12th & $5.72^{*}$ & $(4.86,6.72)$ & $5.48^{*}$ & $(4.64,6.47)$ & $2.27^{*}$ & $(1.96,2.64)$ & $2.26^{*}$ & $(1.94,2.64)$ \\
\hline \multicolumn{9}{|l|}{ BMI } \\
\hline Low/normal & 1.00 & & 1.00 & & 1.00 & - & 1.00 & \\
\hline Overweight & 0.88 & $(0.70,1.11)$ & 0.95 & $(0.74,1.22)$ & 0.91 & $(0.73,1.13)$ & 0.93 & $(0.75,1.16)$ \\
\hline Obese & 1.00 & $(0.75,1.34)$ & 1.21 & $(0.88,1.65)$ & 0.91 & $(0.69,1.20)$ & 0.97 & $(0.73,1.29)$ \\
\hline \multicolumn{9}{|l|}{ Paternal level of education } \\
\hline Some primary school & 1.00 & & 1.00 & & 1.00 & - & 1.00 & \\
\hline Completed middle school & 0.95 & $(0.77,1.17)$ & 0.99 & $(0.76,1.29)$ & 0.83 & $(0.68,1.02)$ & 0.92 & $(0.72,1.19)$ \\
\hline Completed high school & 0.70 & $(0.57,0.87)$ & 0.77 & $(0.58,1.02)$ & 0.84 & $(0.69,1.02)$ & 0.97 & $(0.75,1.27)$ \\
\hline Completed higher education & $0.58^{*}$ & $(0.46,0.74)$ & 0.86 & $(0.60,1.23)$ & 0.75 & $(0.61,0.93)$ & 0.96 & $(0.70,1.32)$ \\
\hline \multicolumn{9}{|l|}{ Maternal level of education } \\
\hline Some primary school & 1.00 & & 1.00 & & 1.00 & - & 1.00 & \\
\hline Completed middle school & 0.93 & $(0.77,1.13)$ & 1.05 & $(0.81,1.35)$ & 0.83 & $(0.69,1.0)$ & 0.89 & $(0.70,1.13)$ \\
\hline Completed high school & 0.73 & $(0.59,0.90)$ & 1.0 & $(0.75,1.32)$ & 0.77 & $(0.63,0.93)$ & 0.84 & $(0.65,1.09)$ \\
\hline Completed higher education & $0.58^{*}$ & $(0.45,0.74)$ & 1.08 & $(0.75,1.55)$ & 0.75 & $(0.60,0.94)$ & 1.02 & $(0.74,1.41)$ \\
\hline \multicolumn{9}{|l|}{ Monthly family income } \\
\hline$<1000 \mathrm{RMB}$ & 1.00 & & 1.00 & & 1.00 & - & 1.00 & \\
\hline 1000-1500 RMB & 1.00 & $(0.64,1.55)$ & 1.13 & $(0.70,1.82)$ & 0.97 & $(0.62,1.51)$ & 0.97 & $(0.61,1.55)$ \\
\hline 1500-2000 RMB & 0.52 & $(0.34,0.80)$ & 0.60 & $(0.37,0.96)$ & 0.84 & $(0.55,1.29)$ & 0.86 & $(0.55,1.36)$ \\
\hline 2000-3000 RMB & 0.65 & $(0.43,0.97)$ & 0.81 & $(0.51,1.27)$ & 0.95 & $(0.64,1.43)$ & 0.98 & $(0.63,1.52)$ \\
\hline 3000-4000 RMB & 0.52 & $(0.35,0.78)$ & 0.71 & $(0.45,1.10)$ & 0.76 & $(0.51,1.13)$ & 0.81 & $(0.53,1.25)$ \\
\hline 4000-5000 RMB & 0.51 & $(0.34,0.78)$ & 0.78 & $(0.49,1.24)$ & 0.81 & $(0.53,1.21)$ & 0.91 & $(0.58,1.42)$ \\
\hline$>$ RMB 5000 & $0.32^{*}$ & $(0.21,0.47)$ & $0.49^{*}$ & $(0.31,0.77)$ & $0.55^{*}$ & $(0.37,0.81)$ & 0.62 & $(0.40,0.95)$ \\
\hline \multicolumn{9}{|l|}{ Subjective SES in province } \\
\hline Low & 1.00 & & 1.00 & & 1.00 & - & 1.00 & - \\
\hline Low middle & 1.11 & $(0.56,2.19)$ & 1.35 & $(0.63,2.90)$ & 0.79 & $(0.41,1.53)$ & 0.78 & $(0.38,1.60)$ \\
\hline Middle & 0.78 & $(0.41,1.53)$ & 1.29 & $(0.61,2.74)$ & 0.83 & $(0.44,1.56)$ & 0.94 & $(0.47,1.92)$ \\
\hline High middle & $0.48^{*}$ & $(0.25,0.92)$ & 1.28 & $(0.59,2.74)$ & 0.67 & $(0.35,1.26)$ & 1.04 & $(0.51,2.14)$ \\
\hline High & $0.37^{*}$ & $(0.18,0.73)$ & 1.44 & $(0.64,3.23)$ & $0.49^{*}$ & $(0.25,0.96)$ & 1.01 & $(0.48,2.15)$ \\
\hline \multicolumn{9}{|l|}{ Subjective SES in school } \\
\hline Low & 1.00 & & 1.00 & & 1.00 & - & 1.00 & - \\
\hline Low middle & 0.79 & $(0.40,1.55)$ & 0.71 & $(0.34,1.50)$ & 0.86 & $(0.44,1.68)$ & 0.84 & $(0.41,1.70)$ \\
\hline Middle & 0.89 & $(0.47,1.69)$ & 0.74 & $(0.37,1.49)$ & 1.04 & $(0.56,1.94)$ & 0.91 & $(0.46,1.77)$ \\
\hline High middle & 0.51 & $(0.27,0.97)$ & $0.44^{*}$ & $(0.22,0.89)$ & 0.71 & $(0.38,1.32)$ & 0.61 & $(0.31,1.19)$ \\
\hline High & $0.41^{*}$ & $(0.21,0.79)$ & $0.45^{*}$ & $(0.22,0.95)$ & $0.48^{*}$ & $(0.25,0.93)$ & $0.48^{*}$ & $(0.24,0.96)$ \\
\hline \multicolumn{9}{|l|}{ Television viewing } \\
\hline None & 1.00 & & 1.00 & & 1.00 & & 1.00 & \\
\hline$>0-2$ hours & $0.81^{*}$ & $(0.69,0.95)$ & $0.81^{*}$ & $(0.68,0.96)$ & $1.21^{*}$ & $(1.05,1.39)$ & $1.21^{*}$ & $(1.04,1.41)$ \\
\hline$>2-4$ hours & 0.70 & $(0.49,1.00)$ & 0.64 & $(0.43,0.96)$ & 0.73 & $(0.51,1.03)$ & 0.75 & $(0.52,1.09)$ \\
\hline$>4$ hours & $0.40^{*}$ & $(0.23,0.70)$ & $0.34^{*}$ & $(0.18,0.64)$ & $0.38^{*}$ & $(0.22,0.66)$ & $0.42^{*}$ & $(0.23,0.76)$ \\
\hline
\end{tabular}


Table 3 Odds ratios (OR) and $95 \%$ confidence intervals $(95 \% \mathrm{Cl})$ of physical inactivity by sedentary behaviors for males ( $\mathbf{N}=\mathbf{5 0 5 7 )}$ (Continued)

\begin{tabular}{|c|c|c|c|c|c|c|c|c|}
\hline \multicolumn{9}{|c|}{ Computer use } \\
\hline None & 1.00 & & 1.00 & & 1.00 & & 1.00 & \\
\hline$>0-2$ hours & 1.04 & $(0.88,1.24)$ & 1.06 & $(0.88,1.28)$ & 1.08 & $(0.92,1.27)$ & 1.00 & $(0.84,1.18)$ \\
\hline$>2-4$ hours & 0.96 & $(0.69,1.35)$ & 1.04 & $(0.71,1.51)$ & 0.81 & $(0.58,1.12)$ & 0.82 & $(0.58,1.16)$ \\
\hline$>4$ hours & $0.56^{*}$ & $(0.36,0.86)$ & 0.64 & $(0.39,1.05)$ & $0.41^{*}$ & $(0.27,0.63)$ & $0.49^{*}$ & $(0.30,0.78)$ \\
\hline
\end{tabular}

Covariate: Grade, BMI, Paternal level of education, Maternal level of education, Monthly family income, Subjective SES in province, Subjective SES in school. ${ }^{1}$ MVPA on 0 days: spent 0 day out of the past 7 days with at least 60 minutes of moderate-to-vigorous physical activity (MVPA).

${ }^{2}$ MVPA on 1-4 days: spent less than 5 days out of the past 7 days with at least 60 minutes of MVPA. ${ }^{*} \mathrm{p}<0.05$.

\section{The prevalence of PA}

The prevalence of achieving recommended PA levels was $19.9 \%$ for all participants; more than one-third (39.9\%) of participants performed $<1 \mathrm{~h}$ PA during the past 7 days. There was a significant difference in the physical activity/inactivity variables between the males and females $(p<0.05)$ with $25.1 \%$ of males being categorized as active compared to $14.6 \%$ of females (Table 2 ).

\section{The prevalence of sedentary behavior}

Approximately $43 \%$ of adolescents reported watching television and $30.2 \%$ reported computer usage (Table 2). There were significant differences in the television viewing/computer use variables between the males and females ( $p s<0.05)$; $5.5 \%$ of males watched television for $>2 \mathrm{~h}$ every day, whereas only $3.9 \%$ of females reported this behavior; $7.2 \%$ of males reported that they used the computer for $>2$ h every day, compared with $3.5 \%$ of females (Table 2).

\section{Factors correlated with physical inactivity}

Baseline univariate logistic models investigating the associations between physical inactivity and the independent variables (Tables 3 and 4) revealed that high-school students (10th-12th grades) were more likely than middle-school students (7th-9th grades) to engage in no PA. Generally, students with higher SES, which included better-educated parents, higher monthly family incomes, and higher subjective SES in the province and the school, were less likely to do no physical activity. BMI was not significantly associated with PA in males or females. In male students, 0-2 h/day television viewing was associated with decreased odds of doing no PA (0 hours MVPA/week) and an increased odds of being insufficiently active. In addition, $>4 \mathrm{~h}$ television viewing was associated with decreased odds of doing no physical activity and being insufficiently active in male students. Television viewing was not significantly associated with participating in no physical activity or insufficient physical activity in female students. More than $4 \mathrm{~h}$ daily computer use was associated with lower odds of no PA and insufficient physical activity in males, but not in females. Conversely, less (0-2 h daily) computer usage was associated with higher odds of physical inactivity in females, but not in males.

After adjustment for covariates, the multivariate model including both sedentary behaviors showed that grade remained associated with higher odds of physical inactivity in males and females (Tables 3 and 4). Higher monthly family income continued to be associated with lower odds of doing no PA in males and females, and insufficient PA in females only. Students with higher subjective SES in school were less likely to perform no PA. Higher subjective SES in school also protected male students from being insufficient physically active (Tables 3 and 4).

Male students who watched television for $0-2 \mathrm{~h}$ or $>4$ h daily were less likely to engage in no PA compared to those with no television viewing (0 hours). In males, watching television for $>4$ h daily had the same effect on no PA and insufficient PA, but $0-2 \mathrm{~h}$ television viewing was associated with a greater probability of insufficient PA. Television viewing was not significantly associated with participating in no physical activity or insufficient physical activity in female students (Tables 3 and 4).

Light (0-2 h) computer use was associated with higher odds of no PA or insufficient PA in females, whereas $>4$ h daily computer use was associated with lower odds of insufficient physical activity in male students. Univariate models including single sedentary behaviors revealed patterns similar to those of the multivariate model (data not shown).

\section{Discussion}

In this sample of Chinese youths, the overall prevalence of physical inactivity $(\sim 80 \%)$ was high. This finding was consistent with those from the United States [28] and South Africa [29]. More than 40\% of participants reported television viewing and 30\% reported computer use, indicating that screen time has continued to increase among Chinese adolescents since 2006 [30].

In agreement with previous research in Canada [10], this study found that patterns of PA and sedentary 
Table 4 Odds ratios (OR) and $95 \%$ confidence intervals $(95 \% \mathrm{Cl})$ of physical inactivity by sedentary behaviors for females $(\mathrm{N}=4844)$

\begin{tabular}{|c|c|c|c|c|c|c|c|c|}
\hline & \multicolumn{4}{|c|}{ No $P A^{1}$} & \multicolumn{4}{|c|}{ Insufficient $\mathrm{PA}^{2}$} \\
\hline & \multicolumn{2}{|c|}{ Univariate } & \multicolumn{2}{|c|}{ Multivariate } & \multicolumn{2}{|c|}{ Univariate } & \multicolumn{2}{|c|}{ Multivariate } \\
\hline & OR & $95 \% \mathrm{Cl}$ & OR & $95 \% \mathrm{Cl}$ & OR & $95 \% \mathrm{Cl}$ & OR & $95 \% \mathrm{Cl}$ \\
\hline \multicolumn{9}{|l|}{ Grade } \\
\hline 7th-9th & 1.00 & & 1.00 & & 1.00 & & 1.00 & \\
\hline 10th-12th & $16.05^{*}$ & $(12.82,20.08)$ & $15.06^{*}$ & $(11.98,18.94)$ & $2.73^{*}$ & $(2.17,3.42)$ & $2.65^{*}$ & $(2.11,3.34)$ \\
\hline \multicolumn{9}{|l|}{ BMI } \\
\hline Low/normal & 1.00 & & 1.00 & & 1.00 & - & 1.00 & \\
\hline Overweight & 1.32 & $(0.87,1.99)$ & 1.00 & $(0.63,1.57)$ & 1.23 & $(0.80,1.89)$ & 1.11 & $(0.71,1.70)$ \\
\hline Obese & 0.77 & $(0.45,1.31)$ & 1.28 & $(0.71,2.30)$ & 1.02 & $(0.60,1.75)$ & 1.12 & $(0.65,1.95)$ \\
\hline \multicolumn{9}{|l|}{ Paternal level of education } \\
\hline Some primary school & 1.00 & & 1.00 & & 1.00 & - & 1.00 & \\
\hline Completed middle school & 1.05 & $(0.82,1.34)$ & 1.09 & $(0.79,1.50)$ & 0.95 & $(0.73,1.22)$ & 0.92 & $(0.67,1.25)$ \\
\hline Completed high school & 0.91 & $(0.71,1.66)$ & 1.35 & $(0.95,1.92)$ & 0.97 & $(0.75,1.26)$ & 1.05 & $(0.75,1.47)$ \\
\hline Completed higher education & $0.59^{*}$ & $(0.45,0.77)$ & 1.37 & $(0.91,2.05)$ & 0.88 & $(0.67,1.15)$ & 1.06 & $(0.72 .1 .56)$ \\
\hline \multicolumn{9}{|l|}{ Maternal level of education } \\
\hline Some primary school & 1.00 & & 1.00 & & 1.00 & - & 1.00 & \\
\hline Completed middle school & 1.03 & $(0.82,1.29)$ & 1.01 & $(0.75,1.37)$ & 1.02 & $(0.80,1.30)$ & 1.08 & $(0.80,1.45)$ \\
\hline Completed high school & 0.73 & $(0.57,0.92)$ & 0.88 & $(0.62,1.23)$ & 0.91 & $(0.71,1.64)$ & 1.05 & $(0.75,1.45)$ \\
\hline Completed higher education & $0.47^{*}$ & $(0.36,0.63)$ & 0.89 & $(0.59,1.34)$ & 0.99 & $(0.75,1.30)$ & 1.41 & $(0.96,2.07)$ \\
\hline \multicolumn{9}{|l|}{ Monthly family income } \\
\hline$<1000 \mathrm{RMB}$ & 1.00 & & 1.00 & & 1.00 & - & 1.00 & \\
\hline 1000-1500 RMB & 1.00 & $(0.57,1.75)$ & 1.07 & $(0.63,2.16)$ & 0.84 & $(0.47,1.51)$ & 0.85 & $(0.46,1.55)$ \\
\hline $1500-2000 \mathrm{RMB}$ & 0.84 & $(0.49,1.46)$ & 1.04 & $(0.57,1.92)$ & 0.95 & $(0.54,1.68)$ & 0.98 & $(0.54,1.77)$ \\
\hline 2000-3000 RMB & 0.62 & $(0.37,1.03)$ & 0.78 & $(0.44,1.41)$ & 0.71 & $(0.42,1.22)$ & 0.72 & $(0.41,1.26)$ \\
\hline $3000-4000$ RMB & 0.67 & $(0.40,1.11)$ & 0.92 & $(0.51,1.65)$ & 0.76 & $(0.45,1.30)$ & 0.75 & $(0.43,1.34)$ \\
\hline 4000-5000 RMB & 0.56 & $(0.34,0.95)$ & 0.82 & $(0.45,1.50)$ & 0.64 & $(0.37,1.09)$ & 0.63 & $(0.35,1.13)$ \\
\hline$>$ RMB 5000 & $0.32^{*}$ & $(0.19,0.53)$ & $0.48^{*}$ & $(0.27,0.87)$ & $0.43^{*}$ & $(0.26,0.73)$ & $0.44^{*}$ & $(0.25,0.78)$ \\
\hline \multicolumn{9}{|l|}{ Subjective SES in province } \\
\hline Low & 1.00 & & 1.00 & & 1.00 & - & 1.00 & \\
\hline Low middle & 0.92 & $(0.34,2.45)$ & 1.18 & $(0.40,3.52)$ & 1.10 & $(0.38,3.16)$ & 1.24 & $(0.41,3.77)$ \\
\hline Middle & 0.56 & $(0.22,1.43)$ & 1.01 & $(0.35,2.95)$ & 0.93 & $(0.34,2.56)$ & 1.21 & $(0.41,3.60)$ \\
\hline High middle & $0.30^{*}$ & $(0.12,0.76)$ & 0.88 & $(0.30,2.59)$ & 0.70 & $(0.25,1.92)$ & 1.14 & $(0.38,3.43)$ \\
\hline High & $0.19^{*}$ & $(0.07,0.50)$ & 0.92 & $(0.30,2.79)$ & 0.48 & $(0.17,1.37)$ & 0.94 & $(0.31,2.90)$ \\
\hline \multicolumn{9}{|l|}{ Subjective SES in school } \\
\hline Low & 1.00 & & 1.00 & & 1.00 & - & 1.00 & \\
\hline Low middle & 1.27 & $(0.47,3.41)$ & 0.94 & $(0.32,2.80)$ & 1.92 & $(0.63,5.81)$ & 1.86 & $(0.59,5.86)$ \\
\hline Middle & 1.26 & $(0.50,3.17)$ & 0.68 & $(0.25,1.90)$ & 1.94 & $(0.68,5.50)$ & 1.79 & $(0.60,5.33)$ \\
\hline High middle & 0.91 & $(0.36,2.28)$ & 0.63 & $(0.23,1.76)$ & 1.61 & $(0.57,4.56)$ & 1.68 & $(0.57,5.00)$ \\
\hline High & $0.47^{*}$ & $(0.18,1.20)$ & 0.49 & $(0.17,1,40)$ & 1.27 & $(0.44,3.66)$ & 1.54 & $(0.51,4.66)$ \\
\hline \multicolumn{9}{|l|}{ Television viewing } \\
\hline None & 1.00 & & 1.00 & & 1.00 & & 1.00 & \\
\hline$>0-2$ hours & 0.91 & $(0.76,1.09)$ & 0.83 & $(0.67,1.03)$ & 1.18 & $(0.98,1.42)$ & 1.02 & $(0.84,1.25)$ \\
\hline$>2-4$ hours & 0.67 & $(0.42,1.06)$ & 0.68 & $(0.40,1.17)$ & 0.77 & $(0.48,1.25)$ & 0.73 & $(0.44,1.21)$ \\
\hline$>4$ hours & 1.30 & $(0.53,3.16)$ & 1.21 & $(0.44,3.30)$ & 0.69 & $(0.25,1.90)$ & 0.63 & $(0.22,1.81)$ \\
\hline
\end{tabular}


Table 4 Odds ratios (OR) and $95 \%$ confidence intervals $(95 \% \mathrm{CI})$ of physical inactivity by sedentary behaviors for females ( $\mathbf{N}=\mathbf{4 8 4 4})$ (Continued)

\begin{tabular}{|c|c|c|c|c|c|c|c|c|}
\hline Computer $\mathrm{C}$ & & & & & & & & \\
\hline None & 1.00 & & 1.00 & & 1.00 & & 1.00 & \\
\hline$>0-2$ hours & $1.35^{*}$ & $(1.09,1.68)$ & $1.42^{*}$ & $(1.10,1.82)$ & $1.57^{*}$ & $(1.26,1.96)$ & $1.58^{*}$ & $(1.24,2.01)$ \\
\hline$>2-4$ hours & 0.95 & $(0.58,1.55)$ & 0.96 & $(0.54,1.71)$ & 0.78 & $(0.46,1.33)$ & 0.84 & $(0.47,1.47)$ \\
\hline$>4$ hours & 2.33 & $(0.81,6.64)$ & 2.66 & $(0.85,8.37)$ & 1.29 & $(0.41,4.02)$ & 1.53 & $(0.48,4.88)$ \\
\hline
\end{tabular}

Covariate: Grade, BMI, Paternal level of education, Maternal level of education, Monthly family income, Subjective SES in province, Subjective SES in school. ${ }^{1}$ MVPA on 0 days: spent 0 day out of the past 7 days with at least 60 minutes of moderate-to-vigorous physical activity (MVPA).

${ }^{2}$ MVPA on 1-4 days: spent less than 5 days out of the past 7 days with at least 60 minutes of MVPA.

${ }^{*} p<0.05$.

behaviors differed between males and females. More male students reported sedentary behaviors, including television viewing and computer use, as well as more physical insufficient activity, and being more physically active than female students, but television viewing was no significantly associated with physical inactivity in females.

The association between screen time and PA differed between males and females. Male students who watched television were less likely to engage in no PA than males who did not watch television, but television viewing was not significantly associated with physical inactivity in females. A similar pattern was observed in male students who reported $>4$ h daily computer use. Female students were more sensitive to computer than to television use, as $0-2 \mathrm{~h}$ daily computer use increased the risk of doing no physical activity or being insufficiently active. This difference might be caused by the different purposes of sedentary behaviors.

The results of a recent study suggested that sedentary behaviors for "productive" purposes were positively associated with PA, whereas television viewing or computer use alone was not [13]. For example, males may prefer to watch sports on television or online, which could motivate them to perform PA, whereas females may prefer other types of program. Thus, further investigation of the effects of different types of sedentary pursuit on PA among Chinese youths is needed.

The findings of a previous study [10] also suggested that computer use competed with television viewing, but this phenomenon was not observed in the present study. Models including single sedentary behaviors revealed patterns similar to those of models including both behaviors, indicating that the two behaviors were independently associated with PA. Some researchers have also hypothesized that time management skills interact with sedentary behavior to influence PA in adolescents [13], but evidence obtained in the present study was insufficient to examine this issue.

High-school students were more likely than middleschool students to be physically inactive, which might be due to two major reasons. Firstly, academic pressure to prepare for the national college entrance examination may be a significant driving force in sedentary behavior. Secondly, age is a contributor, as previous studies showed that there existed an age related decline in physical activity in students [21,31]. Consistent with the findings of previous studies [19], SES was positively associated with PA level in our participants. Adolescents with higher monthly family incomes and subjective SES in school were less likely to perform no PA or to be physically inactive. Financial limitations may impact students' access to many types of PA, such as sports requiring special equipment and motion-controlled video games. Therefore, public playgrounds are necessary to protect adolescents with lower SES from physical inactivity. Meanwhile, in this study, adolescents with better-educated parents were less likely to be physically inactive, which was consistent with previous results and suggested the parental guidance be necessary to ensure proper engagement in these behaviors [32].

This study was limited by the cross-sectional design, which prevented the identification of any causal relationship between sedentary behavior and PA. Thus, future longitudinal studies and further investigations of the association between sedentary behavior purposes and physical inactivity are needed. Meanwhile, social desirability bias might affect the subjective measures of SES, which should be paid attention to in future study.

\section{Conclusions}

Physical inactivity and sedentary behaviors were prevalent in Chinese adolescents. Our study revealed complex relationships between sedentary behaviors and physical inactivity, highlighting the need for targeted interventions. The association between sedentary behavior and physical inactivity differed between males and females, possibly due to differences in the purposes of behaviors. Parental guidance may be necessary to ensure proper engagement in these behaviors. Public facilities are also necessary to encourage students with low SES to engage in physical activities. 


\section{Abbreviations}

BMI: Body mass index; Cl: Confidence interval; MVPA: Moderate to vigorous physical activity; OR: Odds ratio; PA: Physical activity; SES: Socioeconomic status; YRBSS: Youth Risk Behavior Surveillance System.

\section{Competing interests}

The authors declare that they have no competing of interests.

\section{Authors' contributions}

SY and JYwas involved in the design of the study. YC and ZZ were responsible for data collection and analyses. YC wrote the manuscript. All authors have read and approved the final version of the manuscript.

\section{Acknowledgements}

This study was supported by a grant from the National Key Technologies R\&D Program in the 11th 5-year plan of China (no. 2009BAl77B02). The authors would like to thank the following people for their ongoing work in participant recruitment and follow-up at the study sites: Zhengyan Jiang (Zhejiang University), Jing Liu (Peking University), Jianqun Fang (Ningxia Medical University), Wenbing Gao (Chinese Academy of Sciences), Yanqing Tang (China Medical University), Jin Jing (Sun Yat-Sen University), Wenqing Fu (Suzhou University), Yi Huang (Sichuan University), and Wei Hong (Peking University). The authors also thank Yao Yao (Department of Biostatistics, Bioinformatics and Biomathematics, Georgetown University) for her assistance with data analysis.

\section{Author details}

'Department of Orthopedic Surgery, Second Xiangya Hospital, Central South University, \#139 Ren-Min Zhong Road, Changsha 410011, China. ${ }^{2}$ Medical Psychological Institute, Second Xiangya Hospital, Central South University, \#139 Ren-Min Zhong Road, Changsha 410011, China.

Received: 5 November 2013 Accepted: 16 July 2014 Published: 22 July 2014

\section{References}

1. Carrel AL, Clark RR, Peterson SE: Improvement of fitness, body composition, and insulin sensitivity in overweight children in a schoolbased exercise program: a randomized, controlled study. Arch Pediatr Adolesc Med 2005, 159:963-968.

2. Pate RR, Wang CY, Dowda M: Cardiorespiratory fitness levels among US youth 12 to 19 years of age: findings from the 1999-2002 National Health and Nutrition Examination Survey. Arch Pediatr Adolesc Med 2006, 160:1005-1012.

3. Magnussen CG, Thomson R, Cleland VJ: Factors affecting the stability of blood lipid and lipoprotein levels from youth to adulthood: evidence from the Childhood Determinants of Adult Health Study. Arch Pediatr Adolesc Med 2011, 165:68-76.

4. Centers for Disease Control and Prevention: Physical Activity for Everyone. http://www.cdc.gov/physicalactivity/everyone/guidelines/children.html. Accessed March 30, 2011.

5. Loud KJ, Gordon CM: Adolescent bone health. Arch Pediatr Adolesc Med 2006, 160:1026-1032.

6. Menschik D, Ahmed S, Alexander MH: Adolescent physical activities as predictors of young adult weight. Arch Pediatr Adolesc Med 2008, 162:29-33.

7. Allender S, Kremer P, de Silva-Sanigorski A: Associations between activityrelated behaviours and standardized BMI among Australian adolescents. J Sci Med Sport 2011, 14:512-521.

8. Corder K, van Sluijs EMF, Goodyer I: Physical activity awareness of British adolescents. Arch Pediatr Adolesc Med 2011, 165:603-609.

9. Epstein LH, Beecher MD, Graf JL: Choice of interactive dance and bicycle games in overweight and nonoverweight youth. Ann Behav Med 2007, 33:124-131.

10. Serrano-Sanchez JA, Martí-Trujillo S, Lera-Navarro A: Associations between screen time and physical activity among Spanish adolescents. PLoS One 2011, 6:e24453.

11. Koezuka N, Koo M, Allison KR: The relationship between sedentary activities and physical inactivity among adolescents: results from the Canadian Community Health Survey. J Adolesc Health 2006, 39:515-522.
12. Marshall SJ, Biddle SJH, Gorely T: Relationships between media use, body fatness and physical activity in children and youth: a meta-analysis. Int J Obes Relat Metab Disord 2004, 28:1238-1246.

13. Feldman $D E$, Barnett $T$, Shrier I: Is physical activity differentially associated with different types of sedentary pursuits? Arch Pediatr Adolesc Med 2003, 157:797-802.

14. Maher C, Olds T, Mire E: Reconsidering the sedentary behaviour paradigm. PLoS One 2014, 9:e86403.

15. Lee W, Kuo ECY: Internet and displacement effect: children's media use and activities in Singapore. J Comput Mediat Commun 2002, 7:0-0.

16. Fotheringham MJ, Wonnacott RL, Owen N: Computer use and physical inactivity in young adults: public health perils and potentials of new information technologies. Ann Behav Med 2000, 22:269-275.

17. Nelson MC, Gordon-Larsen P, Adair LS: Adolescent physical activity and sedentary behavior patterning and long-term maintenance. Am J Prev Med 2005, 28:259-266

18. Stalsberg R, Pedersen AV: Effects of socioeconomic status on the physical activity in adolescents: a systematic review of the evidence. Scand J Med Sci Sports 2010, 20:368-383.

19. Du H, Bennett D, Li L: Physical activity and sedentary leisure time and their associations with $\mathrm{BMI}$, waist circumference, and percentage body fat in 0.5 million adults: the China Kadoorie Biobank study. Am J Clin Nutr 2013, 97:487-496.

20. Day $\mathrm{K}$, Alfonzo $\mathrm{M}$, Chen $\mathrm{Y}$ : Overweight, obesity, and inactivity and urban design in rapidly growing Chinese cities. Health Place 2013, 21:29-38.

21. Eaton DK, Kann L, Kinchen S: Youth risk behavior surveillance-United States, 2011. MMWR 2012, 61:1-162.

22. Ekelund U, Luan J, Sherar LB: Moderate to vigorous physical activity and sedentary time and cardiometabolic risk factors in children and adolescents. JAMA 2012, 307:704-712.

23. Ji C: Report on childhood obesity in China (1) body mass index reference for screening overweight and obesity in chinese school-age children. Biomed Environ Sci 2005, 18:390-400.

24. Ostrove JM, Adler NE, Kuppermann M: Objective and subjective assessments of socioeconomic status and their relationship to self-rated health in an ethnically diverse sample of pregnant women. Health Psychol 2000, 19:613-618

25. Adler NE, Epel ES, Castellazzo G: Relationship of subjective and objective social status with psychological and physiological functioning: preliminary data in healthy white women. Health Psychol 2000 19:586-592.

26. Cuenca-Garcia M, Huybrechts I, Ruiz JR: Clustering of multiple lifestyle behaviors and health-related fitness in European adolescents. J Nutr Educ Behav 2013, doi:10.1016/j.jneb.2013.02.006.

27. Peterhans E, Worth A, Woll A: Association between health behaviors and cardiorespiratory fitness in adolescents: results from the cross-sectional momo-study. J Adolesc Health 2013, 53:272-279.

28. Singh GK, Yu SM, Siahpush M: High levels of physical inactivity and sedentary behaviors among US immigrant children and adolescents. Arch Pediatr Adolesc Med 2008, 162:756-763.

29. Micklesfield LK, Pedro TM, Kahn K: Physical activity and sedentary behavior among adolescents in rural South Africa: levels, patterns and correlates. BMC Public Health 2014, 14:40.

30. Cui Z, Hardy LL, Dibley MJ, Bauman A: Temporal trends and recent correlates in sedentary behaviours in Chinese children. Int J Behav Nutr Phys Act 2011, 8:93.

31. McVeigh J, Meiring R: Physical activity and sedentary behavior in an ethnically diverse group of South african school children. J Sports Sci Med 2014, 13:371-378.

32. Totland TH, Bjelland M, Lien N: Adolescents' prospective screen time by gender and parental education, the mediation of parental influences. Int J Behav Nutr Phys Act 2013, 10:89.

doi:10.1186/1471-2458-14-744

Cite this article as: Chen et al:: Associations between physical inactivity and sedentary behaviors among adolescents in 10 cities in China. BMC Public Health 2014 14:744. 